\title{
MONITORING AND POLICIES TOWARDS THE MUNICIPALITIES WITH FINANCIAL DIFFICULTIES
}

\author{
N. Markov* \\ Department "Regional Development”, Faculty of Economics, Trakia University, Stara Zagora, \\ Bulgaria
}

\begin{abstract}
Local government in Bulgaria is determined by strong legal regulation, significant imbalances and heterogeneity. Municipalities have different socio-economic and demographic potential. This defines different conclusions regarding the budget process, which is a basic attestation of the volume of municipal commitments and the resources for their implementation. The aim of the study is to present the quantitative measures that define a municipality as "a municipality in difficulty" and on this basis to present some summaries and recommendations. The study uses general and specific methods of assessment and analysis. The results show that a group of municipalities is in permanent financial difficulty. This requires a differentiated approach by the central government to local government.
\end{abstract}

Key words: Municipalities, Budgets, Imbalances, Regulation

\section{PURPOSE}

Differentiation in the development of the different regions in Bulgaria is significant. The coefficient of variations at NUTS2 level reaches almost $50 \%$. This high value gives rise to distinct differences in both the socioeconomic profile and the demographic situation of the different regions. Municipalities as the main administrativeterritorial unit in which local self-government takes place also show unevenness. It is manifested both in population numbers and its characteristics, as well as in the ability of individual municipalities to accumulate revenues that secure public commitments that meet modern quality of life requirements. The size of municipalities in Bulgaria is extremely inadequate. In Bulgaria there is a municipality with a population of less than 1000 people (the municipality of Treklyano as of 31 Dec 2016 has a population of 836 people), and there is also a municipality with a population of more than 1.3 million (Stolichna Municipality). This extremely high variation range also determines the differences in the financial capacity of the individual municipalities in Bulgaria. Under these conditions, it is very important to

*Correspondence to: Nedelin Markov, Department "Regional development", Faculty of economics, Trakia university, Stara Zagora, Bulgaria,E-mail: n_markov@uni-sz.bg develop a uniform methodology for assessing the financial situation of municipalities in order to make qualitative and reliable research findings. A similar methodology was developed by the Ministry of Finance. The methodology defines a set of indicators for comparative analysis and evaluation. In addition, in the Public Finance Act, the valuation element is integrated into a separate block in which the so-called financially troubled municipalities are classified. Financially troubled municipalities are those experiencing financial pressures outlined in a set of indicators related to short-term liquidity, budget balancing and collection of their own revenues. The reason for this classification is the determining of a set of tools for purposeful impact so as to overcome the reported deterioration.

\section{METHODS}

The methodology of the survey is based on a methodology of the Ministry of Finance, which is the result of the provisions of the Public Finance Act and in particular Article 130, which defines financially troubled municipalities and the specific procedures for their rehabilitation. The indicators to be monitored are as follows (1): 1. The annual amount of municipal debt payments for each municipality in each individual year may not exceed 15 per cent of the average annual amount of own revenues 
and the total equalisation subsidy for the last three years calculated on the basis of annual performance reports of the municipality; 2. Payables for budget expenditures of the municipality available at the end of the year exceed by 15 per cent the average annual amount of reported expenditures for the last 4 years;

3. Commitments available for the budget of the municipality at the end of the year exceed 50 per cent of the average annual expenditure reported for the last 4 years; 4. The arrears of municipal budgets available at the end of the year exceed $5 \%$ of the municipal expenditures reported for the last year;
5. The budget balance of the municipality budget in the last three years is a negative figure for each of the three years; 6 . The average collection rate for real estate tax and vehicle tax is below the average collection rate of the two taxes for all municipalities reported for the last year. The indicators described do not have the highest valuation value, but they provide a satisfactory basis for comparison even more so that the most reliable data are used in their calculation.

\section{RESULTS}

Table 1 summarises the presented information.

Table 1. Allocation of municipalities by number of indicators for financial valuation.

\begin{tabular}{|c|c|c|c|c|}
\hline & $\begin{array}{c}\text { Two } \\
\text { criteria }\end{array}$ & $\begin{array}{c}\text { Three } \\
\text { criteria }\end{array}$ & $\begin{array}{c}\text { Four } \\
\text { criteria }\end{array}$ & $\begin{array}{c}\text { Five } \\
\text { criteria }\end{array}$ \\
\hline $\begin{array}{c}\text { Number of } \\
\text { municipalities }\end{array}$ & 42 & 27 & 4 & 5 \\
\hline
\end{tabular}

Source: Ministry of Finance, Public expenditures, Municipal finances

Towards the end of 2016, a total of 36 (2) municipalities are classified as financially hindered municipalities. This conclusion is based on the fact that they violate more than three criteria defined in the Public Finance Act. This is a litmus for existing problems about the ability of municipalities to fulfill their commitments to the local community. The legislator has stipulated that municipalities with similar difficulties should follow a strict procedure aimed at their financial rehabilitation. The process of financial recovery leads to a loss of autonomy since the central government gets greater rights to intervene in municipal finances. On the other hand, the rescue procedure entitles municipalities to request additional loans and subsidies from the central government. With regard to the current debt payment (Criterion 1 of the LFA) by the end of 2016, 23 municipalities report data higher than the ones set. For example, the municipality of Madzharovo reports a value of $90.8 \%$, municipality of Oryahovo - $66.9 \%$, and municipality of Miziya - 53.0\%. The other municipalities with a reported excess achieve lower values.

With respect to the criterion the cost obligations do not exceed $15 \%$ of the average annual amount of expenses over the last 4 years (Criterion 2), the status being as follows. The criterion was not adhered to by 37 municipalities with the highest values being the municipalities of Dospat (104\%), Belogradchik (94\%) and Nedelino (71\%).

The indicator reflecting expenditure commitments not to exceed the average annual amount of expenses was violated by 36 municipalities. The highest values are reported in the municipalities of Smolyan (182\%), Chepelare (145\%) and Lesichevo (120\%). The municipality of Nedelino has high value here again (110\%).

The limit of $5 \%$ of the arrears of municipal expenditures is exceeded by 58 municipalities. The largest deviations are reported in the municipalities of Belogradchik (104\%), Dospat (83\%), Dimovo (82\%) and Nedelino (63\%). Negative budget balance for a given period was realized by the municipalities of Blagoevgrad, Sozopol, Shabla, Belene, etc. Interesting is the presence of Stolichna municipality, which has budget deficit in three consecutive years, as follows: 2014 - BGN 84.2 million, 2015 - BGN 35.7 million and 2016 - BGN 38.4 million.

\section{CONCLUSION}

It is difficult to typify precisely which group of municipalities tend to be financially troubled. It would be logical for a small municipality with low income capacity and limited municipal ownership to have high tendency and risk of falling into the group of financially troubled municipalities. How then could we explain the presence of the municipality of 
Sozopol, which has unbalanced budget, high levels of debt and overdue liabilities. Isn't it that the Black Sea coast municipalities belong to those "dwarf municipalities" which, due to the tourist service they offer, obtain disproportionate municipal revenues compared to any other inland municipality of this magnitude. The reasons for this can be sought in the following areas:

$>$ The size of the municipalities - in Bulgaria there are to date 265 municipalities. Some of them have emerged due to accepted traditions, others for political reasons, still others have municipality status due to their large size and are therefore a natural attraction center for people, activities and services. Whatever the reason, the fragmentation is extremely high. In our country we have a municipality that is already under a thousand people (Treklyano municipality). We also have a municipality with more than 1.3 million people. And although a proven direct link between population and income capacity cannot be sought, the following will be pointed out just for the sake of evidence. Treklyano municipality generates its own revenue of only $8 \%$ of its total revenue and manages to cover only $17 \%$ of its costs for local activities with own revenues. This extremely low income capacity predetermines two paths for development. The first one - the municipality maintains low level of expenditures and does not make commitments above its available resources. This results in a balanced budget and low debt. The second path - the municipality makes greater expenses than what is affordable. This leads to indebtedness and overdue liabilities. If it takes the first path, municipal finances will be stable. However, this will lead to a low supply of public goods and services. However, today's society has ever higher demands to the environment it lives in, and part of it (mostly the younger and more capable) will be oriented to other more attractive places. If the municipality chooses the second path of development, it will be more attractive to its community, but municipal finances will be unstable and the municipal government will be insecure and unpredictable due to pressure by creditors.

$>$ The political environment - the political environment in Bulgaria is far from being in line with the notions of modern politics. The political toolkit can be defined as one that creates inefficiency in local selfgovernment in two channels. Firstly, policy making does not guarantee that the most well-prepared and motivated employees will join the municipal administration; Secondly, political commitments create inefficiency in the spending of public funds, mainly through violation of public procurement legislation. In this connection, short-sighted methods of distribution of vertical transfers have been found - there is no reliable algorithm to regulate how to allocate the funds from the central government to the municipalities, beyond the estimates stipulated in the State Budget Act. Again linked to political dependencies is the fact that some municipalities are more privileged to receive funding. Such considerations can also be made with the receipt of interest-free loans from the central government;

$>$ Limitation on civil control and the direct participation in local government - almost 30 years after the beginning of the democratic changes in our country, there are no efficient mechanisms for the implementation of civil control in the field of local self-government, incl. in the field of local finances. Moreover, the current legislation excludes budget issues from being the subject of a local referendum;

On the basis of the conclusions drawn, the following recommendations can be defined:

1. Reform in the administrative-territorial division - the scale of Bulgarian economy does not allow the maintenance of such fragmented local self-government. The adopted structure in Bulgaria leads to the maintenance of unnecessary administration, as well as to the provision of services inadequate to modern conditions, both in quantity and quality. The large number of municipalities and the lack of real insight into the needs of local communities result in the effects of the Wallace Oates theorem (3). The effect of this theorem takes into account the existence of surpluses and deficits in the individual municipalities, which in its cumulative effect results in loss of prosperity for the whole society. Urgent reform is needed in the structure of local self-government, taking into account not only the geographic and traditional characteristics of the settlements, but also their specific nature. Only more unified administrative and territorial units can cope with environmental, transport, utility, etc. issues;

2. Developing new rules to finance large capital expenditures by small municipalities through debt - it sounds paradoxical, but it 
is true that small municipalities with limited budget opportunities engage in bonding relations with different creditors to secure their own contribution in various projects. This results in an increase in municipal indebtedness. It is necessary for the central government to provide a guarantee mechanism to grant state guarantees for the implementation of certain projects by small to medium-sized municipalities. Such projects with state guarantees could be in certain priority areas such as environment, technical infrastructure, etc.;

3. Development of a procedure for granting subsidies and interest-free loans to municipalities with permanent difficulties, as well as further development of the methodology for distribution of the common and targeted subsidies, to be most in line with the characteristics of the individual municipalities.

\section{REFERENCES}

1. Law of public finances, Promulgated, SG No. 15/15.02.2013, effective 1.01.2014, amended, SG No. 95/8.12.2015, effective 1.01.2016, amended and supplemented, SG No. 43/7.06.2016

2. Financial Indicators of Municipalities in Bulgaria, Data of Ministry of Finance, www.minfin.bg

2. Oates, W., Journal of Economic Literature, Vol. 37, No. 3., pp. 1120-1149, 1999 